\title{
ARTÍCULOS
}

\section{NUDO TERRITORIAL Y DESTERRITORIALIZACIÓN INDÍGENA EN LOMA CAMPANA (NEUQUÉN, ARGENTINA) DESDE 1963'.}

\author{
Sabrina Aguirre \\ Universidad Nacional del Comahue \\ aguirrecarlasabrina@gmail.com
}

\begin{abstract}
Resumen: El escrito analiza cómo las políticas estatales provinciales configuraron nudos territoriales en la zona donde se ubica la comunidad Campo Maripe, al norte de Añelo, el corazón de la formación geológica Vaca Muerta. Se sostiene que estas políticas diseñaron los espacios impulsando territorialidades asociadas a determinadas actividades económicas y trajeron como consecuencia la desterritorialización indígena. La comunidad Campo Maripe, cuyo territorio actualmente se superpone parcialmente con el yacimiento hidrocarburífero Loma Campana -uno de los tres más relevantes en la extracción por métodos no convencionales-, ha sido seleccionada como caso de estudio en función de la notoriedad de sus estrategias de resistencia durante los últimos años. Se utilizan fuentes escritas y orales para caracterizar el complejo panorama de la superposición de territorialidades a partir de las políticas provinciales y el desarrollo de dinámicas específicas en las interacciones de los diferentes actores dentro de los nudos territoriales.
\end{abstract}

Palabras clave: Políticas, nudos territoriales, desterritorialización, conflicto, comunidades indígenas, hidrocarburos.

Tittle: TERRITORIAL KNOT AND INDIGENOUS DETERRITORIALIZATION IN LOMA CAMPANA (NEUQUEN, ARGENTINA) SINCE 1963.

\begin{abstract}
The paper analyses how Neuquen's state policies configured territorial knots in the area where the mapuce community Campo Maripe is located, in northern Añelo, the core of the Vaca Muerta geological formation. It is argued that these policies designed spaces boosting certain economic activities and their associated territorialities and brought indigenous deterritorialization as a consequence. The Mapuce community Campo Maripe, whose territory currently partially overlaps with the Loma Campana oil field -one of the three most important fields in the extraction of hydrocarbons by non-conventional methods-, has been selected as a case study due to how notorious its resistance strategies have become over the last few years. Written documents and oral testimonies are used to characterize the complex scenario of territorial overlapping caused by state policies and the development of specific interactions between the different actors within the territorial knots.
\end{abstract}

Keywords: Policies, territorial knots, deterritorialization, conflict, indigenous communities, hydrocarbons.

\footnotetext{
${ }^{1}$ Este trabajo se enmarca en el Proyecto Unidades Ejecutoras (IPEHCS-CONICET-UNCO) titulado "La (re)producción de las desigualdades en la Patagonia Norte. Un abordaje multidimensional" (22920180100046CO).
}

Recibido: 17-05-2021

Aceptado: $30-05-2021$

Cómo citar este artículo: AGUIRRE, Sabrina. Nudo territorial y desterritorialización indígena en Loma Campana (Neuquén, Argentina) desde 1963. Naveg@mérica. Revista electrónica editada por la Asociación Española de Americanistas [en línea]. 2021, n. 27. Disponible en: <http://revistas.um.es/navegamerica>. [Consulta: Fecha de consulta]. ISSN 1989-211X. 


\section{Introducción}

El espacio social, según Henri Lefebvre, es producido en la medida en que es apropiado por el capitalismo, por relaciones de producción, por la integración al mercado o a la producción industrial, configurándose espacios dominantes y dominados $^{2}$. De la mano de aportes de la geografía y la sociología dedicadas a analizar las transformaciones del mundo rural en las últimas décadas, particularmente de Rogerio Haesbaert, comprendemos al territorio como dialéctico y dinámico, en tanto su producción depende de la tensión entre territorialización y desterritorialización, dada por el cambio constante de relaciones y condiciones en el espacio $^{3}$. En este sentido, la desterritorialización ocurre cuando se fuerza la movilidad de un conjunto de actores que no tienen posibilidad de reterritorializarse acorde a su propia voluntad ${ }^{4}$.

Cuando un grupo social dominante extiende su territorialidad sobre espacios previamente ocupados, desterritorializa a otros actores, frecuentemente caracterizando a las zonas anexadas como desiertas ${ }^{5}$. De esta forma se generan solapamientos conflictivos de territorialidades, dando lugar a lo que se ha definido como "nudos territoriales", espacios donde "la dialéctica de territorialidades asume mayor intensidad. De un lado, un Estado que trata sucesivamente de avanzar su malla territorial capitalista mediante la planificación y el '(des)ordenamiento' territorial; del otro, las territorialidades de distintas comunidades, pueblos y nacionalidades"6.

El avance armado del Estado argentino sobre los espacios hasta entonces dominados por las sociedades indígenas, a fines del siglo XIX, desplazó la frontera del modelo agroexportador argentino. Por lo tanto, se trató de un evento constitutivo del Estado nacional ${ }^{7}$. Sus consecuencias han sido abordadas mediante el estudio de las "huellas del genocidio" durante la primera mitad del siglo $X X^{8}$. Las políticas neuquinas en relación al pueblo mapuce ${ }^{9}$ han sido analizadas en términos del

2 LEFEBVRE, Henri. La producción del espacio. Papers: revista de sociología. 1974, n. 3, pp. 219-229.

3 HAESBAERT, Rogerio. El mito de la desterritorialización. Del "fin de los territorios" a la multiterritorialidad. México: Siglo XXI, 2011. 328 p.

${ }_{4}^{4}$ HAESBAERT, Rogerio. Del mito de la desterritorialización a la multiterritorialidad. Cultura y representaciones sociales [en línea]. 2013, vol. 8, n. 15, pp. 9-42. [Consulta: 04-05-2021]. Disponible en <http://www.scielo.org.mx/pdf/crs/v8n15/v8n15a1.pdf>.

${ }^{5}$ BORG RASMUSSEN, Mattias y LUND, Christian. Reconfiguring frontier spaces: the territorialization of resource control. World Development. 2018, n. 101, pp. 388-399.

${ }^{6}$ BONILLA, Omar [et al.]. Nudos territoriales críticos en Ecuador: dinámicas, cambios y límites en la reconfiguración territorial del Estado. GeoGraphos [en línea]. 2016, vol. 7, n. 84, pp. 66-68. [Consulta: 04-05-2021]. Disponible en <https://rua.ua.es/dspace/bitstream/10045/53465/1/Omar Bonilla.pdf>.

${ }^{7}$ PAPAZIAN, Alexis. Pliegues genocidas en Estados nacientes: el genocidio armenio en Turquía y el genocidio indígena en Argentina. Revista de Estudios sobre Genocidio [en línea]. 2018, n. 13, pp. 1125. [Consulta: 04-05-2021].

Disponible

en $<$ http://revistas.untref.edu.ar/index.php/reg/article/view/255>.

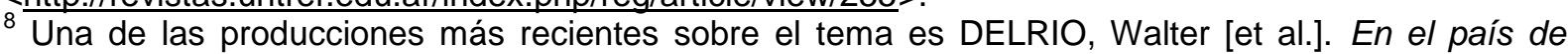
nomeacuerdo. Archivos y memorias del genocidio del Estado argentino sobre los pueblos originarios, 1870-1950. Viedma: Universidad Nacional de Río Negro, 2018. 325 p.

${ }_{9}$ Para las palabras en mapuzungun, idioma mapuce, utilizamos el grafemario Ragileo, utilizado por el pueblo en la actualidad. Una de sus implicancias es la escritura de "mapuce" en lugar de "mapuche". Cuando se cite un original en que se escriba de otro modo, no será modificado. 
proceso de configuración de alteridades ${ }^{10}$ y del asimilacionismo ${ }^{11}$.

Este trabajo busca analizar cómo las políticas estatales provinciales configuraron usos de los espacios, a través del estudio de la zona donde se ubica actualmente la comunidad Campo Maripe, en Añelo, corazón de Vaca Muerta. Sostendremos que allí se impulsó la territorialización del capital mediante diferentes actividades y de esta forma se promovió la desterritorialización mapuce, generando nudos territoriales. Las políticas diseñadas y aplicadas por el gobierno de la provincia de Neuquén definieron territorios para ser utilizados con determinados fines económicos, y también buscaron delimitar lugares para la reproducción de la vida indígena y su desarrollo económico, político y cultural. De esta manera, entre 1963, fecha de inicio del primer gobierno provincial $^{12}$, y la actualidad se fueron desplegando, entrando en crisis o consolidando territorialidades vinculadas a los grupos indígenas, a individuos dedicados al comercio, a la ganadería, a empresas dedicadas a la fruticultura y la forestación y más tarde a las vinculadas a la actividad hidrocarburífera.

Todo esto implicó la generación de dinámicas específicas en el territorio y trajo consecuencias para los grupos mapuce que habitan este espacio, que respondieron con diferentes estrategias para sobrevivir y reclamar derechos. La comunidad Campo Maripe, compuesta por 144 personas distribuidas en 35 familias $^{13}$, cuyo territorio actualmente se superpone parcialmente con el yacimiento Loma Campana uno de los tres más importantes en la extracción de hidrocarburos por métodos no convencionales- ha sido seleccionada como caso de estudio en función de la notoriedad de sus estrategias de resistencia durante los últimos años ${ }^{14}$.

Este trabajo forma parte de una investigación en historia que analiza las relaciones entre las organizaciones mapuce y la política neuquina a lo largo del siglo XX y hasta la actualidad. Hemos utilizado fuentes escritas, como documentos oficiales, judiciales y otros producidos por organismos no gubernamentales, y orales, provenientes de trabajo de campo etnográfico y de instancias judiciales. Se inicia el recorrido caracterizando el territorio bajo estudio, tras lo cual se pasa revista a dos conjuntos de políticas del Estado neuquino -las económicas y las indígenas-, que ha estado desde 1963 gobernado por el partido local denominado Movimiento Popular

\footnotetext{
${ }^{10}$ FALASCHI, Carlos; SÁNCHEZ, Fernando y SZULC, Andrea. Políticas indigenistas en Neuquén: pasado y presente. En: BRIONES, Claudia (ed.). Cartografías Argentinas. Políticas indigenistas y formaciones provinciales de alteridad. Buenos Aires: Antropofagia, 2005, pp. 179-221.

${ }^{11}$ LENTON, Diana. Política indigenista argentina: una construcción inconclusa. Anuário antropológico [en línea]. 2010, v. 35, n. 1, pp. 57-97. [Consulta: 04-05-2021]. Disponible en <https://journals.openedition.org/aa/781>.

${ }_{12}$ Tras la etapa previa conocida como territoriana, en la cual el Territorio Nacional de Neuquén dependía directamente del poder central argentino.

${ }_{13}$ VILLARREAL, Jorgelina y HUENCHO, Luisa. Informe Histórico-antropológico. Relevamiento territorial Lof Campo Maripe. Pueblo Mapuce. Neuquén: Provincia de Neuquén, p. 40.

${ }^{14}$ RADOVICH, Juan Carlos. Fractura hidráulica y conflicto territorial en la comunidad mapuche Campo Maripe, Neuquén, Argentina. Revista GeoPantanal [en línea]. 2017, vol. 12, n. 22, pp. 89-104. [Consulta: 04-05-2021]. Disponible $<$ https://periodicos.ufms.br/index.php/revgeo/article/view/3806>; MARAGGI, Inés. Conflictos Geográfico [en línea]. 2020, vol. 42, n. 1, pp. 35-55. [Consulta: 04-05-2021]. Disponible en $<$ http://revele.uncoma.edu.ar/htdoc/revele/index.php/geografia/article/view/2701/59490>.
} 
Neuquino (MPN) $)^{15}$. En ello se pone énfasis en el contraste entre una línea fundacional con influencia del desarrollismo, durante las primeras tres décadas de vida provincial, y una neoliberal instalada a partir de los noventa. Finalmente, se abordan las consecuencias de todo ello en Añelo y la forma en que la comunidad Campo Maripe afrontó los resultados de las políticas provinciales.

\section{El corazón de Vaca Muerta: territorio y población}

La provincia de Neuquén se ubica en el norte de la Patagonia argentina. Posee un área cordillerana ubicada al oeste, y una zona mesetaria al este. De sus 94.078 kilómetros cuadrados, aproximadamente 86.800 forman parte de la denominada "Cuenca Neuquina", reservorio de hidrocarburos de una extensión total de 124.000 kilómetros cuadrados. Dentro de ella se ubica la formación geológica Vaca Muerta. Tras el avance de la frontera nacional sobre los territorios indígenas hacia el sur -con la llamada "Conquista del desierto" (1878-1885) que buscó la expulsión o exterminio de estos pueblos- el primer espacio dinamizado a partir de la producción ganadera ovina y bovina fue la franja oeste, que por sus características fisiográficas fue el lugar de asiento de las primeras grandes explotaciones capitalistas. En el este, cuyas tierras no eran propicias para el ganado de mayores valores, se dio una caprinización de la mano de pequeños productores indígenas y no indígenas descapitalizados y desterritorializados que fueron expulsados de la zona cordillerana por la presencia del latifundio ${ }^{16}$.

Una de las zonas orientales en que se dio este fenómeno fue el departamento de Añelo, que cuenta con una superficie de 11.655 kilómetros cuadrados. Dentro de él, al sur, se ubica la actual localidad homónima con una extensión de 7.303 kilómetros cuadrados. La zona bajo estudio se mantuvo como un espacio marginal durante toda la primera mitad del siglo XX. Su geografía cuenta con extensos espacios de árida meseta, atravesados por el valle del río Neuquén (figura 1). En términos de sus actividades económicas, la más dinámica en la primera mitad del siglo XX era el comercio minoritario ${ }^{17}$, de la mano de migrantes sirios que diversificaron sus actividades incluyendo la ganadería y de esta manera acumularon capital suficiente para adquirir tierras en la meseta en 1972. La ganadería en la zona era primordialmente caprina ${ }^{18}$, lo cual indicaba la escasa disponibilidad de capital de los productores. De la superficie del departamento, la titularización como propiedad privada de la tierra era sumamente reducida, rondando el $5,3 \%$, y solo el $10,1 \%$ de

\footnotetext{
${ }^{15}$ Este partido provincial nació en 1961, durante la proscripción del peronismo, ofreciéndose como la alternativa local para sus adeptos, aunque posteriormente decidió colocarse por fuera del armado propiciado por el General Perón a su retorno del exilio. Se caracterizó por enarbolar las banderas del federalismo por oposición a la toma de decisiones desde el centro del poder nacional. Como veremos aquí, su derrotero puede caracterizarse considerando una etapa fundacional atravesada por el desarrollismo y otra en la que adquirió rasgos neoliberales.

${ }^{16}$ BANDIERI, Susana. Condicionantes históricos del asentamiento humano después de la ocupación militar del espacio. En: BANDIERI, Susana; FAVARO, Orietta y MORINELLI, Marta (comps.). Historia de Neuquén. Buenos Aires: Plus Ultra, 1993, pp. 109-146.

17 DALMAUX, Ana María y MICHAU, Analía. Proceso de ocupación del Valle de Añelo [tesis de licenciatura]. Neuquén: Universidad Nacional del Comahue, 1989. 79 p.

${ }^{18}$ Mendoza Gobierno. 1947 - Cuarto censo General de la Nación. Tomo II [en línea]. [Consulta: 0505-2021]. Disponible en <http://www.deie.mendoza.gov.ar/\#!/censos-productivos/1947-cuarto-censogeneral-de-la-nacion-42>.
} 
aquel total se encontraba puesto en producción para mediados del siglo ${ }^{19}$.

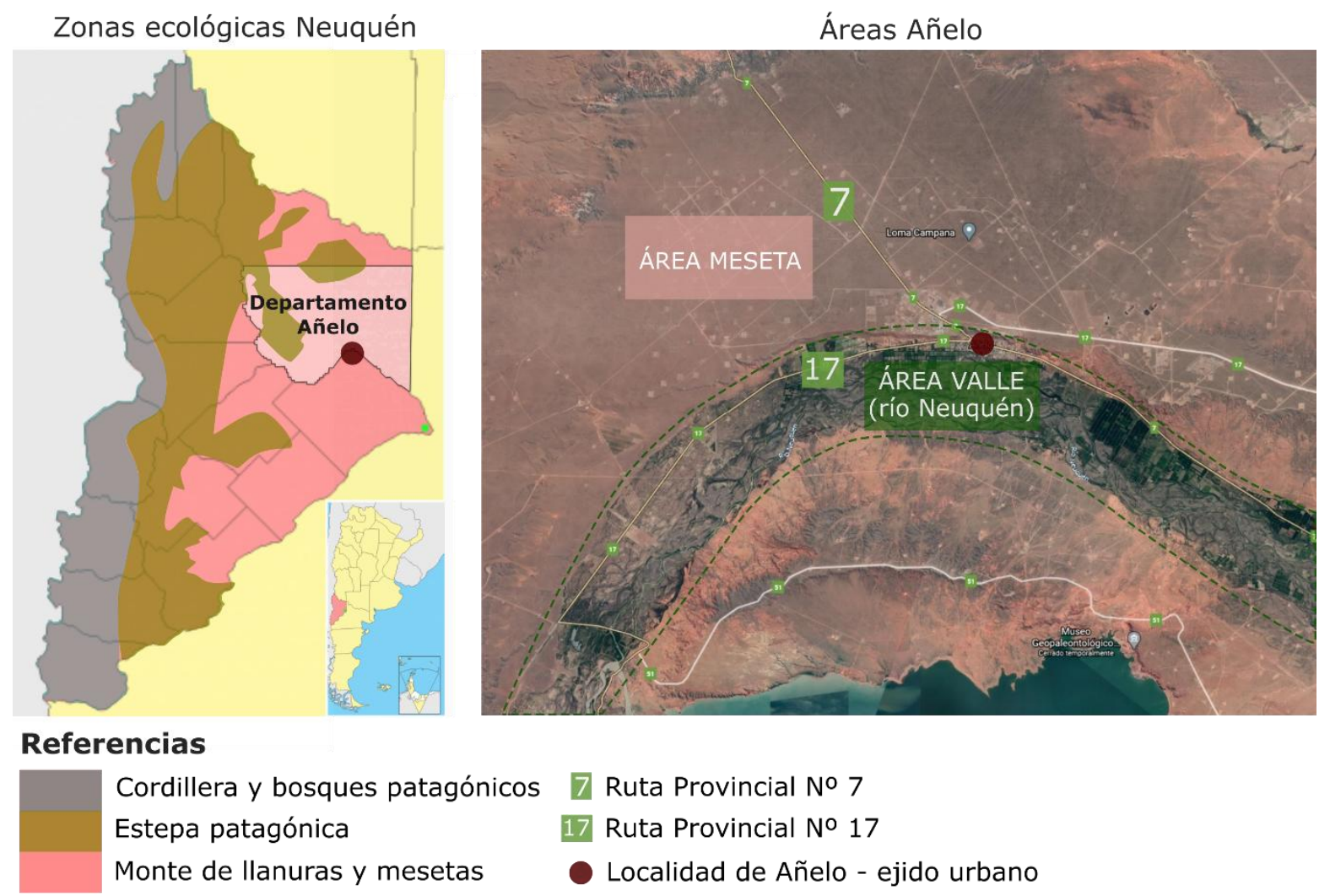

Fig. 1: Áreas de Neuquén y Añelo. Fuente: Elaboración propia.

Entre los años sesenta y los noventa, Neuquén atravesó una reconfiguración demográfica a causa de la inmigración proveniente de otras zonas argentinas, que generó un esquema con desbalances poblacionales internos ${ }^{20}$. Por una parte, más de la mitad de la población residía en el área de la confluencia, denominada de esta manera por la unión entre los ríos Neuquén y Limay, espacio donde se ubica la capital provincial. Allí los principales sectores económicos eran la agricultura intensiva a partir de canales de riego construidos a principios del siglo, la extracción de hidrocarburos y actividades de procesamiento de los productos de ambos ${ }^{21}$.

Por otra parte, se configuraron grandes áreas de escaso poblamiento. El departamento de Añelo se mantuvo en esta última situación: en la localidad homónima para 1970 se registraba un total de 239 habitantes. El desarrollismo en su versión provincial buscó aplicar políticas de fijación de población y despegue económico. Esto trajo un primer conjunto de consecuencias sobre las que volveremos más adelante. Lejos de haberse extinguido, perduraban en el área familias indígenas, algunas de las cuales serían reconocidas por el Estado de la

\footnotetext{
${ }^{19}$ Ibídem.

${ }^{20}$ PERREN, Joaquín. "Una transición demográfica en el fin del mundo". La población de la provincia de Neuquén (Patagonia, Argentina) durante el siglo XX tardío. Scripta Nova [en línea]. 2009, vol. 13. [Consulta: 28-07-2021]. Disponible en <http://www.ub.edu/geocrit/sn/sn-282.htm>.

21 FAVARO, Orietta (comp.). Sujetos sociales y políticas. Historia reciente de la Norpatagonia Argentina [en línea]. Buenos Aires: La Colmena, 2005. 223 p. [Consulta: 04-05-2021]. Disponible en $<$ http://biblioteca.clacso.edu.ar/Argentina/cehepyc-uncoma/20110414103131/favaro.pdf>.
} 
provincia de Neuquén como comunidad.

Entre los sesenta y los noventa en la provincia se configuraron dos áreas particularmente dinámicas: la cordillerana del sur por su desarrollo turístico y el este -especialmente los departamentos de Zapala y Confluencia- por su rol dentro de la producción de hidrocarburos. No todos los espacios con gas y petróleo podían explotarse a causa de las limitaciones tecnológicas. Si bien desde los años setenta se sintió en Añelo la influencia de la actividad hidrocarburífera, por la explotación por métodos convencionales de gas al sur de la localidad, sólo con la llegada de los métodos no convencionales se tornó rentable el avance sobre zonas que se transformaron en el corazón de la actividad ligada al shale ${ }^{22}$ en Neuquén. Esto supuso un segundo conjunto de consecuencias que examinaremos en breve, poniendo especial atención al derrotero de la comunidad Campo Maripe.

\section{Las políticas provinciales a través del tiempo}

En 1963 asumía el cargo de gobernador de la provincia Felipe Sapag con la tarea de resolver las carencias en infraestructura y el bajo nivel de vida de los habitante ${ }^{23}$. La influencia desarrollista marcó la línea de acción fundacional del MPN. Neuquén fue una de las zonas sobre las que se puso atención, en función de sus recursos hidroenergéticos ${ }^{24}$. El esquema para toda la Patagonia era uno en el que el desarrollo era planificado desde el centro nacional a partir de islas de crecimiento $^{25}$, lo cual en esta provincia fue acompañado por la proyección de actividades como la agricultura -especialmente la fruticultura para exportación- y la forestación. El Estado fue comprendido como un agente central de estos proyectos, lo que se puso de manifiesto en la creación del Consejo de Planificación y Acción para el Desarrollo (COPADE) en 1964. A través de este organismo se diseñó el Plan de Desarrollo Provincial. Uno de los ejes centrales que se comunicaban era la intención de "lograr un crecimiento armónico y balanceado de todos los sectores" ${ }^{26}$.

Otra política dirigida a subsanar las carencias en el nivel de vida de la población fue el reconocimiento de una serie de comunidades indígenas, a las cuales se destinaron porciones de tierra en calidad de reservas indígenas, en un clima de ideas aún orientado hacia la necesidad de incorporar de forma subordinada a los pueblos originarios ${ }^{27}$. Estas acciones permitieron apuntalar la organización de

\footnotetext{
${ }^{22}$ El shale o roca de esquisto es arena compacta donde se produjo el hidrocarburo, que debe ser abierta mediante la inyección de agua para liberarlo. Esto se conoce como una perforación no convencional.

${ }^{23}$ PERREN, Joaquín. "Erase una vez en la Patagonia". Luces y sombras de la economía neuquina (1958-1991). Observatorio de la Economía de la Patagonia [en línea]. 2007. [Consulta: 04-05-2021]. Disponible en <https://www.eumed.net/oe-pat/>.

${ }^{24}$ ARIAS BUCCIARELLI, Mario. Identidades en disputa. Las regiones del Comahue y los poderes provinciales. Cuadernos del Sur [en línea]. 2007, n.35/36, pp. 1-17. [Consulta: 28-07-2021]. Disponible en < http://bibliotecadigital.uns.edu.ar/pdf/csh/n35-36/n35-36a06.pdf >.

${ }^{25}$ CABRAL MARQUES, Daniel. Una relectura histórica de los impactos socio-territoriales de las megainversiones promovidas en el marco de la Patagonia Austral Argentino-Chilena: ¿Distintas formas de desarrollo inducido o meras estrategias de espacialización desregulada de vectores de expansión capitalista? Perfiles Económicos [en línea]. 2016, n. 1, pp. 119-145. [Consulta: 28-072021]. Disponible en <https://revistas.uv.cl/index.php/Perfiles/article/view/609>.

${ }^{26}$ CDCT. Registro № 3331-318. Provincia del Neuquén. Plan de desarrollo provincial... Op. cit., p. 8.

27 VALVERDE, Sebastián. La historia de las organizaciones etnopolíticas del pueblo mapuche.
} 
algunas comunidades, aunque en un contexto poco favorable para la demostración pública de la pertenencia étnica, muchas familias quedaron por fuera de este beneficio, especialmente en la zona este de la provincia, caracterizada por los documentos de la década de 1970, junto con el norte neuquino, como la zona de mayor ocultamiento del idioma y otras pautas culturales ${ }^{28}$. Hasta 1993, se registraron treinta y dos comunidades y algunas de las que quedaron por fuera de este reconocimiento reiniciarían sus procesos organizativos a partir de fines de la década de 1990.

En los setenta la agricultura en el valle del río Negro y el valle inferior del río Neuquén era comprendida desde los proyectos provinciales como "una de las principales fuentes de producción" 29 , con lo cual se ideó la extensión de las áreas de riego y el apoyo financiero para los productores. La actividad hidrocarburífera aún no se iba a consolidar como la de mayor importancia provincial, en parte debido a que las regalías obtenidas por la provincia eran calculadas, acorde a la ley № 17.319 de 1967 , como un $12 \%$ a partir del valor del hidrocarburo en boca de pozo, y no del valor internacional del recurso ${ }^{30}$. Con el fin de colonizar las zonas en las que la extensión de esta actividad era posible, se elaboró la Ley № 263, Código de Tierras Fiscales, en 1961, que luego fue sucesivamente modificada. A partir de esta normativa se podía adjudicar en venta o arrendamiento -con posterior posibilidad de titularización- lotes en los que se llevara adelante un proyecto productivo controlado por la provincia.

En la década de 1980, se registraban algunos cambios, especialmente en torno a la actividad petrolera. Durante el gobierno de facto (1976-1983) se había favorecido la participación privada en el sector, que para 1980 había pasado de un $25 \%$ a un $40 \%{ }^{31}$. Además, a partir de 1981 las regalías provinciales se iban a calcular a partir del precio internacional del crudo. En el gobierno provincial de Pedro Salvatori (1987-1991) los planes de desarrollo aún señalaban la necesidad de "acelerar el proceso de industrialización y diversificación de las actividades productivas"32. Durante este gobierno se desarrolló una primera fase de la disputa entre sectores del partido hegemónico, de la cual salió victoriosa la facción liderada por Jorge Omar Sobisch, quien fue electo gobernador para el siguiente término $(1991-1995)^{33}$.

Revista de Historia [en línea]. 2005, n. 10, pp. 167-177. [Consulta: 05-05-2021]. Disponible en <http://revele.uncoma.edu.ar/htdoc/revele/index.php/historia/article/view/223>.

28 RODRÍGUEZ, Edgardo. Análisis socioeconómico, aspectos culturales y tipología de las comunidades aborígenes del Neuquén. Neuquén: Consejo Federal de Inversiones, 1978.

${ }^{29}$ CDCT. Registro № 2620-222. Consejo de Planificación y Acción para el Desarrollo (en adelante COPADE). Cursos de acción a corto plazo. Tomo III. 1977, p. 5.

${ }^{30}$ FAVARO, Orietta. Estado, política y petróleo. La historia política neuquina y el rol del petróleo en el modelo de provincia, 1958-1990 [tesis doctoral]. La Plata: Universidad Nacional de La Plata, 2001. [Consulta: 05-05-2021]. Disponible

en $<$ http://www.memoria.fahce.unlp.edu.ar/library?a=d\&c=tesis\&d=Jte131 >.

FAVARO, Orietta (comp.). Sujetos sociales y políticas... Op. it., p. 9.

32 CDCT. Registro № 4445-473. COPADE. Neuquén. Estrategia para el desarrollo. 1988, p. 7.

33 RAFART, Gabriel. Las "partes" del Movimiento Popular Neuquino. Un ensayo de interpretación de sus tiempos partidarios. Revista de la Facultad de Derecho y Ciencias Sociales [en línea]. 2009, n. 15, pp. 93-113. [Consulta: 05-05-2021]. Disponible en <https://fadeweb.uncoma.edu.ar/extension/publifadecs/revista/revista15/05GabrielRafart.pdf >. 
Esta gestión apoyó los procesos de privatización neoliberal a nivel nacional e inició el alejamiento respecto de las orientaciones iniciales del MPN. A mediados de la década de 1990 planteó la posibilidad de redefinir la provincia mediante la profundización de los procesos de privatizaciones, la revisión de los regímenes laborales del sector público, el otorgamiento de un rol central en la dinámica económica al sector privado y la vinculación con el sistema financiero internacional ${ }^{34}$, alineándose entonces con la tónica neoliberal nacional del momento. Si bien entre 1995 y 1999 retornó Felipe Sapag al gobierno provincial, su nuevo plan de desarrollo, denominado "Plan Neuquén 2020", sólo alcanzó a ponerse en práctica durante dos años para ser luego abandonado con el inicio de un nuevo término de Sobisch, que esta vez duraría hasta 2007. Con la caída del precio del petróleo y la previsión del agotamiento de las reservas dentro de un lapso de entre diez y veinte años como contexto, Sapag había buscado impulsar la agricultura y la forestación, señalando como actividades complementarias al turismo, la energía y la minería ${ }^{35}$.

Con la asunción de Sobisch para un nuevo mandato, el eje de la política económica pasó a ser el tejido de "alianzas estratégicas" con empresas multinacionales y la reducción del gasto público, en un contexto internacional de subida del precio del petróleo hasta $2008^{36}$. Para este entonces también se hallaba modificada la orientación del gobierno en materia indígena. Precisamente en los espacios impactados por las mayores actividades lucrativas de la provincia -las petroleras y las turísticas-, el solapamiento de las territorialidades del capital y de los indígenas supuso el desarrollo de pugnas especialmente en el sur cordillerano y en el centro y el este provincial. En este contexto, en la provincia de Neuquén, "no ha habido adecuaciones normativas a los avances constitucionales ni al nuevo paradigma jurídico de la diversidad cultural y la situación de conflictos en los territorios ha aumentado significativamente" ${ }^{37}$.

Finalizada la gestión de Sobisch, la de Jorge Sapag (2007-2015) no implicó un cambio de rumbo. Al igual que su antecesor tuvo una política de renovación anticipada de las concesiones de tierras para las empresas hidrocarburíferas, a pedido de estas y poniendo de manifiesto el rol del Estado provincial como garante de su acumulación. El nuevo rumbo provincial no estuvo exento de debates internos dentro del MPN, aunque estos no lograron modificar la tónica general de los siguientes gobiernos. En cuanto al reconocimiento territorial indígena, la provincia reemplazó la creación de reservas por una predilección hacia el uso de la ley de tierras fiscales № 263, a la que ya hemos hecho alusión. Esto significaba que la posibilidad de titularizar tierras ahora era individual y dependía de la presentación de proyectos de desarrollo monitoreados y aprobados por el Estado, solo si los espacios reclamados fueran fiscales. Si se presentaban disputas por superficies ya

\footnotetext{
${ }^{34}$ BILDER, Ernesto y GIULIANI, Adriana. La Economía Política de la Provincia de Neuquén (19832008). En: XII Jornadas Interescuelas de Departamentos de Historia. San Carlos de Bariloche: Universidad Nacional del Comahue, 2009.

${ }^{35}$ CDCT. Registro № 5595-608. COPADE. Neuquén 2020: Crisis y oportunidad. 1997.

${ }^{36}$ DI RISIO, Diego [et al.]. (comps.). Zonas de sacrificio. Impactos de la industria hidrocarburífera en Salta y Norpatagonia. Buenos Aires: América Libre, 2012. 248 p.

${ }_{37}$ GOMIZ, Micaela. La propiedad comunitaria indígena en la provincia de Neuquén. En: III Congreso Nacional de Derecho Agrario Provincial. Neuquén, 2015, p. 2.
} 
privatizadas, el camino a seguir iba a ser la judicialización ${ }^{38}$.

Además de ello, la provincia ha intentado reglamentar normativas nacionales de forma restrictiva. A nivel nacional se cuenta con la Ley № 23.302 , de política indígena y apoyo a las comunidades aborígenes, del año 1985, donde se explicita: "Se entenderá como comunidades indígenas a los conjuntos de familias que se reconozcan como tales por el hecho de descender de poblaciones que habitaban el territorio nacional en la época de la conquista" (artículo 2). Sin embargo, la provincia ha colocado requisitos adicionales a los requeridos por el Registro Nacional de Comunidades Indígenas para reconocer a una agrupación, mediante el Decreto № 1184 del año 2002. En función de ello, esta normativa fue declarada inconstitucional en el año 2013, aunque la provincia aún no la ha derogado ${ }^{39}$. Todas estas consideraciones resultan centrales para analizar el caso de Añelo como nudo territorial y el de Campo Maripe como comunidad indígena dentro de él en particular.

\section{Añelo y su conformación como nudo territorial}

\subsection{Políticas de desarrollo y territorialidades solapadas}

Cada etapa de las políticas provinciales, la desarrollista y la neoliberal, supuso un impulso a la creación de territorialidades dominantes en Añelo que supusieron procesos de desterritorialización indígena. No obstante, por las características de cada modo de acumulación, los procesos de expulsión territorial revistieron singularidades. A su vez, se situaron en momentos diferentes del proceso de organización del pueblo mapuce, lo cual dio a ambas coyunturas salidas diferentes por parte de los indígenas.

Por un lado, en la década de 1970 empezó a sentirse el efecto del crecimiento a partir de la agricultura frutícola planificada de San Patricio del Chañar, localidad ubicada a unos 50 kilómetros de Añelo. Por el otro, también se descubría, en 1977, gas en el yacimiento Loma La Lata, sobre la margen sur del río Neuquén. De manera que en esta área iniciaba la tensión entre dos modelos productivos y dos diseños del espacio: uno vinculado a actividades principalmente frutícolas y forestales, y el otro, a las hidrocarburíferas. En el contexto del gobierno de la línea fundacional del MPN, la apuesta por el primero de ellos era palpable en Añelo. Al ponerse en marcha los mecanismos de la ley de tierras fiscales, se privatizaron algunas parcelas en torno a Añelo entre 1970 y 1974 (figura 2). Esto respondía a los planes provinciales que buscaban extender las zonas bajo riego e impulsar el aprovechamiento agrícola y forestal del espacio.

\footnotetext{
${ }^{38}$ Jorge Lara. Testimonio en la audiencia del 16 de abril de 2019. Causa № 31.024, "Campo, Albino y otros s/ usurpación (art.181)". Registro audiovisual de la autora.

${ }^{39}$ Corte Suprema de Justicia de la Nación. Fallo en "Confederación Indígena del Neuquén c/ Provincia del Neuquén s/ acción de inconstitucionalidad". 10 de diciembre de 2013. Expediente № $615 / 02$.
} 


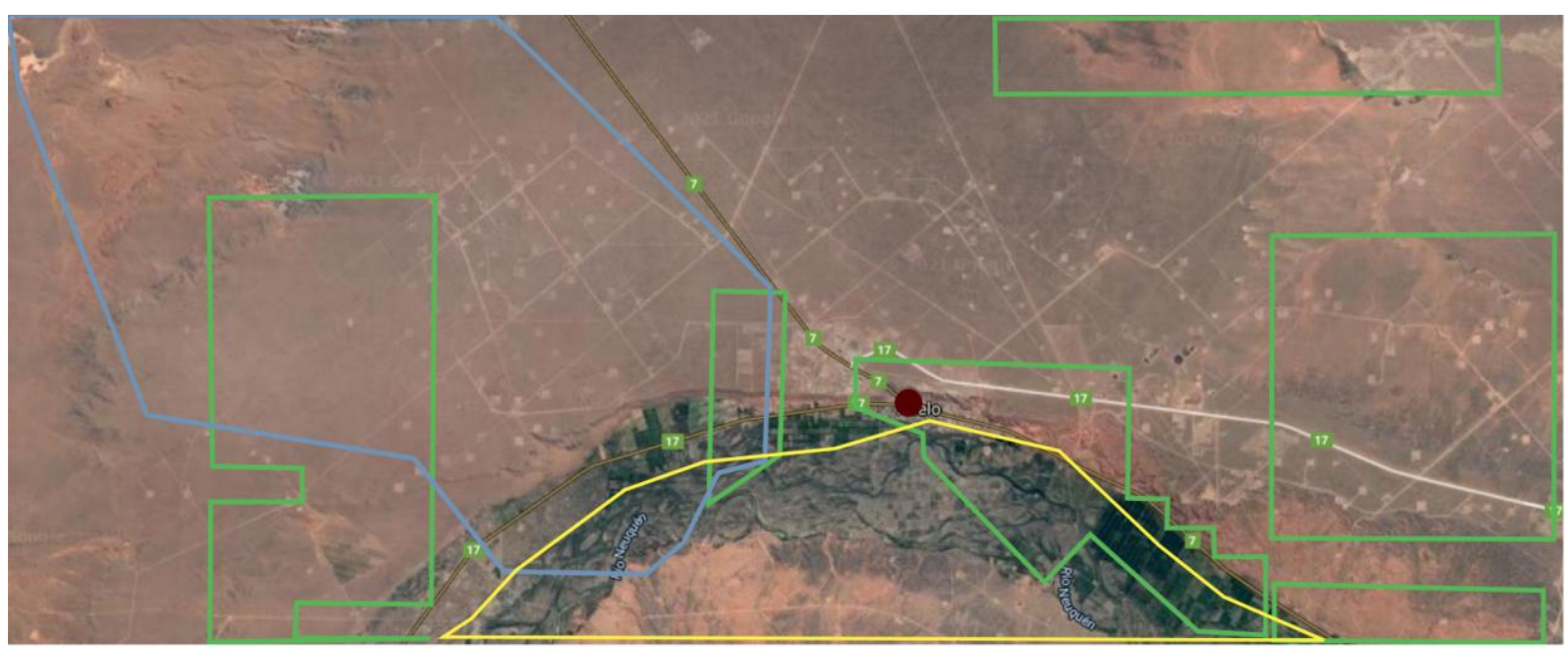

\section{Referencias}

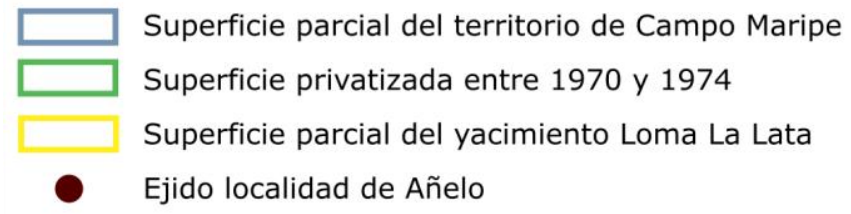

Fig. 2: Solapamientos territoriales en torno a Añelo en la década de 1970. Fuente: Elaboración propia $^{40}$.

La explotación de hidrocarburos -aún por métodos convencionales- supuso una atracción de población que hizo que el número de habitantes ascendiera de 239 (en 1970) a 412 (en 1980 $)^{41}$. En la década de 1980 los planes de desarrollo provincial relevaron en Añelo 600 hectáreas bajo riego dedicadas a la actividad agricultora o forestal, y se colocaron como objetivo sumar 8.700 más, aunque solo se llegaría, para 1997, a 1.950 en total (ver figura 3$)^{42}$. El impulso de la segunda actividad se llevó adelante tanto de la mano de privados como de la empresa estatal Corporación Forestal Neuquina (CORFONE).

${ }^{40}$ En base a Archivo General de la Nación, Archivo Intermedio (en adelante AGN-AI), Fondo Ministerio del Interior, Expedientes Generales, Caja 109, Expediente № 117117, COPADE, Informe sobre el proyecto de colonización de Guañacos, foja 31; FAVARO, Orietta y ANGELINI, Cristina. La situación de las tierras fiscales en la provincia del Neuquén (1957-1977). En: BANDIERI, Susana; LOTITO, María Cristina y VARELA, Gladys (comps.). Neuquén: un siglo de historia. Neuquén: Universidad Nacional del Comahue; Cooperativa de Agua Luz y Fuerza, 1983, pp. 159-165.

${ }^{41}$ DALMAUX, Ana María y MICHAU, Analía. Proceso de ocupación del Valle de Añelo... Op. cit.

42 KUGLER, Norberto. Programa de diversificación productiva y modernización del Estado de la Provincia del Neuquén. Neuquén: Ministerio Nacional de Economía y Obras y Servicios Públicos, 1998. $90 \mathrm{p}$. 


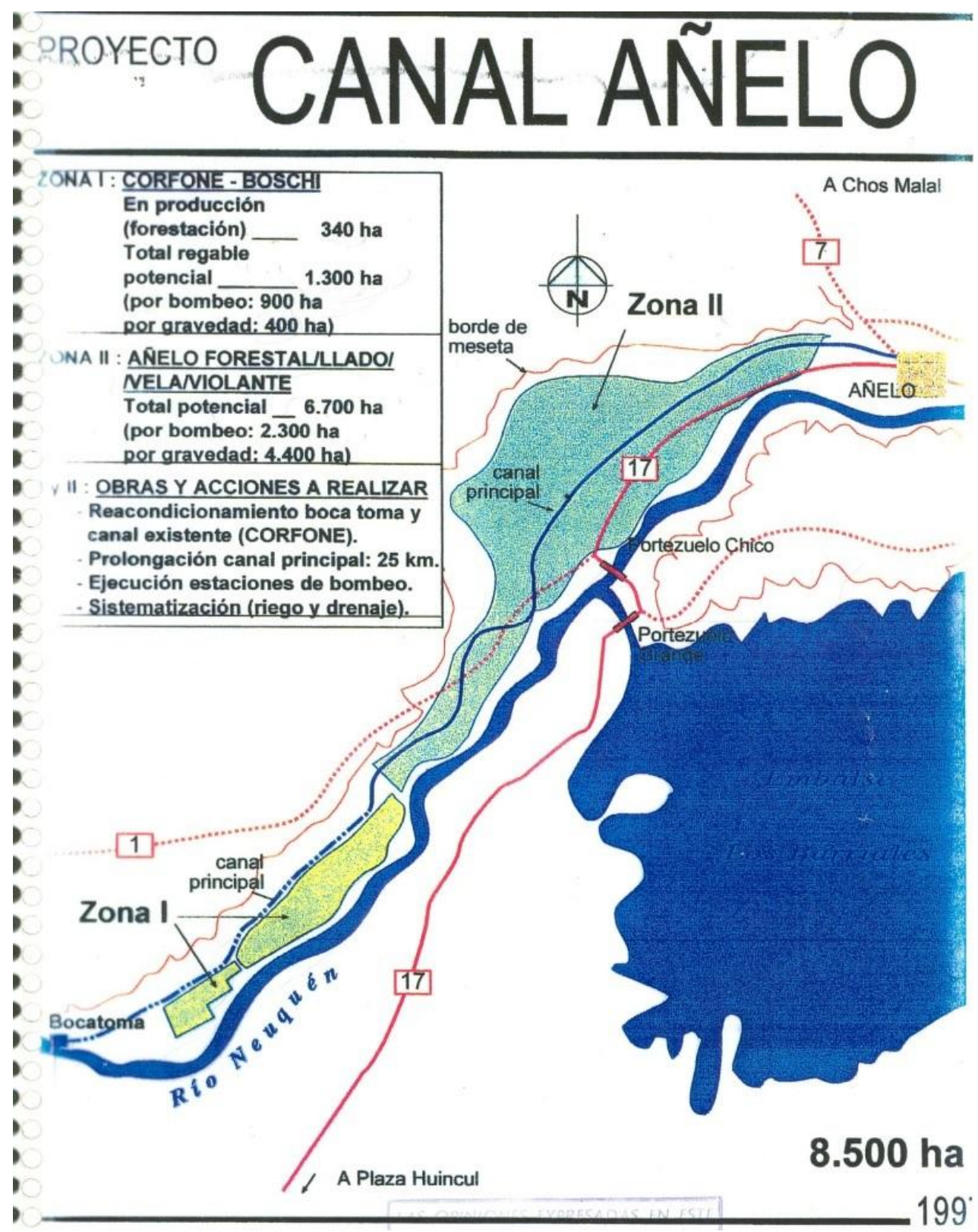

Fig. 3: Zonificación de Añelo en el Plan Neuquén 2020. Fuente: DÍAZ, María Noemí. Evaluación de componentes regionales por microregión y selección de una muestra. Neuquén: COPADE, 1997, p. 94.

En 1997, como ya mencionamos, el gobierno provincial iniciaba su último plan de desarrollo en clave diversificadora, el "Neuquén 2020". La microregión de Añelo era uno de sus ejes principales de acción a corto plazo, una vez más apostando por la agricultura y la forestación ${ }^{43}$, concentrándose especialmente en los aproximadamente cincuenta kilómetros de recorrido del río Neuquén al oeste de Añelo y apostando al sector privado como actor central del desarrollo local. El espacio se diseñó a partir de dos zonas, que demarcaban superficies a lo largo del recorrido del río Neuquén, como muestra la figura 3. La zona I se componía de diecisiete propiedades privadas de grandes extensiones, entre las cuales estaban las de empresas frutícolas (Boschi) y forestales (CORFONE). La zona II se

\footnotetext{
${ }^{43}$ CDCT. Registro № 5595-608. COPADE. Neuquén 2020... Op. cit.
} 
conformaba con setenta y dos productores, de los cuales cuarenta y seis poseían menos de diez hectáreas ${ }^{44}$. Los mayores propietarios eran una empresa inmobiliaria originaria de Buenos Aires -con 9.709 hectáreas-, CORFONE -con 6.096 hectáreas-, la provincia -con 1.998 hectáreas- y una serie de familias, que poseían en total 10.376 hectáreas. Una de ellas era la dueña de los comercios minoristas desde el temprano siglo XX y la otra era la titular de la fracción del lote № 15 en conflicto con los indígenas ${ }^{45}$.

Entre la década de 1980 e inicios de la de 1990 se había afirmado la importancia de esta zona en materia de reservas de gas, con la construcción de gasoductos que permitieron que el yacimiento Loma La Lata abasteciera a La Pampa, Buenos Aires, Córdoba, Mendoza, San Juan y Santa Fe (gasoducto Centro-Oeste) y se conectara con Bahía Blanca con el fin de ser allí industrializado (gasoducto Neuba II) ${ }^{46}$. Para 1990, la población en Añelo llegaba a 1.031 habitantes -recuérdese que en 1980 era de $412^{47}$. Este número seguiría creciendo sobre la base de la explotación de hidrocarburos, por lo que se trató fundamentalmente de un aporte masculino al poblamiento.

Los planes de desarrollo zonal orientados a la diversificación de las actividades productivas y al fortalecimiento y extensión de la agricultura bajo riego encontraron en las disputas políticas hacia adentro del partido provincial gobernante un límite a su desenvolvimiento. Jorge Omar Sobisch, asumió un segundo mandato como gobernador en 1999. Al año siguiente se elaboró un pacto entre YPF y REPSOL por el cual se prorrogaba anticipadamente la concesión de Loma La Lata hasta el año $2027^{48}$. Esto ponía de manifiesto la opción por construir "alianzas estratégicas" con empresas multinacionales, lo cual siguió siendo, aunque sin esa formulación expresa, parte de las gestiones siguientes ${ }^{49}$. En esa línea, Jorge Sapag (2008-2015) también prorrogó anticipadamente las concesiones vigentes, en favor de YPF, Petrobras, Pan American Energy, Apache, Capex, entre otras ${ }^{50}$. El carácter casi bilateral de la relación del gobierno provincial con estas empresas se profundizó a partir de 2006 con la Ley № 26.197 que transfirió del ámbito nacional al provincial la administración de los yacimientos. La provincia pasó a ser el ámbito de control de concesiones, cobro de cánones y regalías, al mismo tiempo que las empresas se posicionaban mejor, al tener que negociar con administraciones locales cuyos presupuestos son dependientes de los hidrocarburos ${ }^{51}$.

\footnotetext{
${ }^{44}$ KUGLER, Norberto. Programa de diversificación... Op. cit. p. 5

${ }^{45}$ DÍAZ, María Noemí. Evaluación... Op. cit.

${ }^{46}$ BLANCO, Graciela. El petróleo en Neuquén: 100 años de historia (1918-2018). Neuquén: Provincia de Neuquén, 2018, p. 167.

47 CDTC. Biblioteca General. Registro № 4438. COPADE. Síntesis Regional. Región Añelo Pehuenches. Documento de Trabajo № 4 del Proyecto "Instrumentación del sistema provincial de planificación del desarrollo". 2011.

${ }^{48}$ BILDER, Ernesto y GIULIANI, Adriana. La Economía Política... Op. cit.

${ }^{49}$ DI RISIO, Diego [et al.]. (comps.). Zonas de sacrificio... Op. cit.

50 Las polémicas renegociaciones de concesiones petroleras de Sapag. Noticias [en línea]. 16-022018. [Consulta: 05-05-2021]. Disponible en <https://noticias.perfil.com/noticias/general/2018-02-16las-polemicas-renegociaciones-de-concesiones-petroleras-de-sapag.phtml>.

${ }^{51}$ PÉREZ ROIG, Diego. La expansión de la frontera hidrocarburífera en Neuquén durante los 2000. Un análisis de sus causas y consecuencias. En: IV Jornadas de Becarios y Tesistas. Buenos Aires: Universidad de Quilmes, 2014.
} 
En la zona de Añelo, los otros sistemas productivos presentes en el territorio se vieron forzados a retraerse, frente al avance de la explotación petrolera. En fecha tan temprana como 1991, otras comunidades de la zona -Paynemil y Kaxipayiñiniciaron procesos de protesta frente a las empresas hidrocarburíferas que actuaban en Loma La Lata ${ }^{52}$. Este panorama iba a profundizarse en el nuevo siglo con la llegada de los métodos no convencionales de extracción, que permitieron la ampliación de las zonas en explotación hacia la meseta, especialmente luego del 2011, año en que se iniciaron las labores vinculadas a la fractura hidráulica.

Por el contrario, el avance de la frontera hidrocarburífera en la zona no generó en otros actores el nivel de oposición exhibido por los indígenas. Sujetos capitalizados a partir de actividades variadas -comerciales, ganaderas, forestales, frutícolas- que habían adquirido tierras en la meseta lograron adaptarse a la dinámica hidrocarburífera mediante la firma de convenios que los colocaron como "superficiarios", es decir, cobrar un canon por la afectación sobre sus parcelas del despliegue hidrocarburífero. Este fue el caso, por ejemplo, de una de las familias consideradas pioneras de la zona que previamente se dedicaba al comercio y la ganadería ${ }^{53}$. La posibilidad de abandonar las actividades en determinado espacio y relocalizarlas en otro gracias al capital acumulado, desde la perspectiva teórica de Rogerio Haesbaert ${ }^{54}$, no compone un caso de desterritorialización, lo cual implica una diferencia fundamental en las posibilidades de readaptación de estos sujetos y de los indígenas.

Si bien se conocía la existencia de los recursos en la zona de Loma Campana yacimiento parcialmente superpuesto con el territorio de Campo Maripe- la posibilidad rentable de extraerlos solo se presentó tras los avances tecnológicos estadounidenses que en aquellas fechas se pusieron en práctica en Neuquén. En el 2013 YPF firmó un acuerdo con Chevron para el desarrollo de Vaca Muerta. Dentro de la provincia, tres zonas se perfilaron como los principales enclaves de la explotación de hidrocarburos no convencionales: el ya mencionado Loma Campana, Bandurria Sur y Amarga Chica. El primero, hasta 2020, contaba con seiscientas perforaciones, dentro de las cuales se hallaban cinco de los diez pozos de mayor producción petrolera a nivel nacional -en los puestos cuatro al ocho ${ }^{55}$. Para este entonces Añelo ya era conocida como "la capital del Shale"56.

El avance de la actividad sobre el territorio al oeste de Añelo durante la última

\footnotetext{
52 BALAZOTE, Alejandro y RADOVICH, Juan Carlos. Proyecto Mega: disputa territorial y reconocimiento étnico de los mapuche de Kaxipayiñ. Relaciones de la Sociedad Argentina de Antropología. 2001, n. 26, pp. 110-117; MARAGGI, Inés. Conflictos territoriales y resistencia mapuche... Op. cit.

${ }_{53}$ Cuatro generaciones en Añelo. Río Negro [en línea]. 20-10-2015. [Consulta: 05-05-2021]. Disponible en <https://www.rionegro.com.ar/cuatro-generaciones-en-anelo-FCRN 7970606/>.

${ }_{54}^{54}$ HAESBAERT, Rogerio. Del mito de la desterritorialización a la multiterritorialidad... Op. cit.

${ }^{55}$ MOTTURA, David. En Vaca Muerta están 7 de 10 pozos petroleros más productivos. Más energía [en línea]. 07-02-2020. [Consulta: 05-05-2021] Disponible en <https://mase.Imneuquen.com/vacamuerta/en-estan-7-cada-10-pozos-petroleros-mas-productivos-n682830>.

${ }^{56}$ TRPIN, Verónica y RODRíGUEZ, Daniela. Transformaciones territoriales y desigualdades en el norte de la Patagonia: extractivismo y conflictos en áreas agrarias y turísticas. Albuquerque: revista de historia [en línea]. 2018, vol. 10, n. 20, pp. 50-66. [Consulta: 05-05-2021]. Disponible en $<$ https://ri.conicet.gov.ar/handle/11336/89750>
} 
década ha sido notable. Desde el 2011 cada vez mayores extensiones de tierra de la meseta ubicada entre las Rutas Provinciales № 17 y № 7 han sido destinadas a la apertura de caminos internos, instalación de infraestructura y radicación de pozos de extracción. En particular se ha intensificado el uso del suelo entre la margen al norte de la Ruta 17 y el sur de la Ruta 7, en un espacio que coincide con el utilizado tradicionalmente por Campo Maripe. Mientras las perforaciones convencionales tenían una zona de gran concentración al sur de la Ruta 17 -entre esta y el Río Neuquén-, aquellos vinculados a la explotación no convencional se radicaron mayormente al norte de la arteria de circulación mencionada, hacia el oeste entrando en disputa con el territorio de Campo Maripe y superponiéndose también a otros usos previos- y el este de Añelo, como podemos observar en la figura 4.

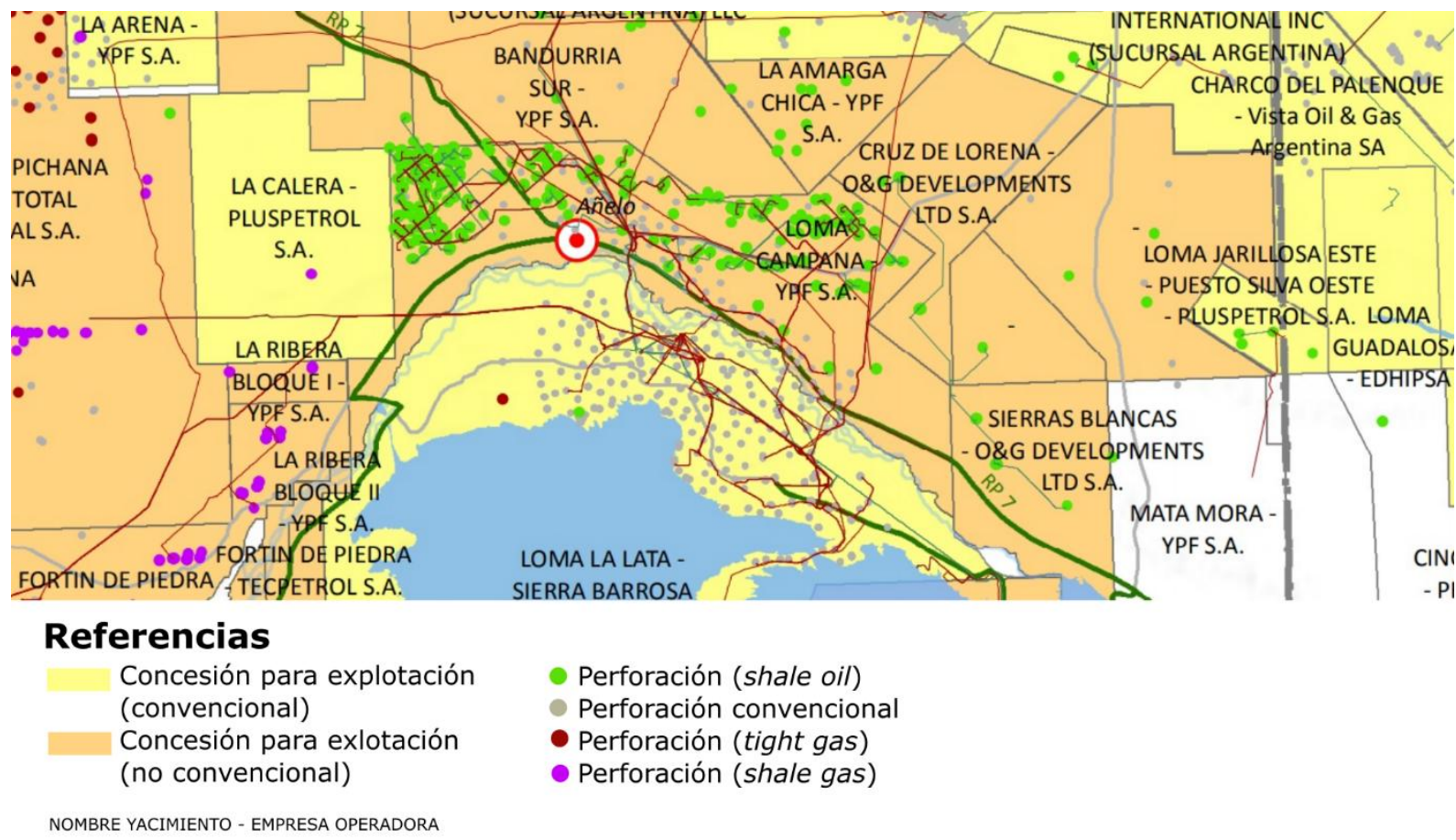

Fig. 4: Localización de las perforaciones en Añelo. Fuente: Dirección Nacional de Información Energética. Mapa "Vaca Muerta" [en línea]. 2019. [Consulta: 05-05-2021]. Disponible en $<$ http://www.energia.gob.ar/contenidos/archivos/Reorganizacion/mesa vaca muerta/mapa vm/VACA \%20MUERTA v6 03-01-2019.pdf>.

\subsection{Nudo de territorialidades, desterritorialización y reorganización de Campo Maripe}

La comunidad Campo Maripe tiene su origen en el arribo a Añelo, en 1927, de la familia compuesta por Pedro Campo, Celmira Maripe Huenchucan y cinco de sus hijos, quienes habían huido de su comunidad de origen, ubicada en el "Fundo de Ralco" (Chile). Allí se insertaron como habitantes de tierras fiscales, específicamente en los lotes $\mathrm{N}^{\circ} 15, \mathrm{~N}^{\circ} 4$ y $\mathrm{N}^{\circ} 6$ de lo que se conocía como "Fortín Vanguardia" ${ }^{57}$. De ellos, el primero se ubica más al sur y está atravesado por el río, mientras los dos restantes son plenamente mesetarios y se encuentran hacia el norte. La reterritorialización de esta familia en la zona se había producido luego de

\footnotetext{
${ }^{57}$ VILLARREAL, Jorgelina y HUENCHO, Luisa. Informe... Op. cit., p. 40.
} 
experimentar directamente la violencia del Estado chileno durante su avanzada sobre las zonas al sur del río Bío Bío ${ }^{58}$. En este panorama y frente al crecimiento de la estigmatización de la identidad indígena, no se mantuvo contacto con otras comunidades -en la zona existen dos más, Paynemil, desde la década de 1900 y Kaxipayiñ, reorganizada en la de 1990- ni se reivindicó abiertamente la pertenencia étnica.

La situación mapuce en la tierra no iba a revestir mayores complejidades hasta que en 1972 se dio la privatización de un sector del lote № 15, en favor de una familia con un emprendimiento dedicado a la actividad forestal. De este modo se inició un solapamiento de actores indígenas y privados -familias y empresas dedicadas a la forestación y la agricultura- que dio paso a un conflicto territorial. En principio, en 1978 los mapuce fueron desalojados de su vivienda por estos nuevos propietarios y las autoridades locales. Esto generó el desmembramiento de la unidad familiar y la disolución del funcionamiento comunitario sostenido hasta entonces. Mientras algunos integrantes de la tercera generación indígena -nietos de los pobladores originales- se vieron forzados a migrar del espacio rural, otros de la segunda y tercera fueron absorbidos como mano de obra en el emprendimiento forestal. Esta relación laboral, acorde a los testimonios actuales, no fue registrada ya que incluyó a niñas de ocho y diez años, y no implicaba el goce de un salario ${ }^{59}$.

Destruida la vivienda familiar de los mapuce ${ }^{60}$, el ganado colectivo y los puestos debieron ser trasladados en sentido norte, hacia la meseta. Una de las integrantes de la tercera generación, Susana Campo, permaneció a cargo de la majada, cada vez más reducida por los constantes traslados forzosos a causa de los conflictos con los nuevos propietarios de la tierra. Debido a la necesidad de que los animales permanecieran cerca del cuerpo de agua, Susana y sus seis hermanos -nietos de Campo y Maripe Huenchucan- protagonizaron una serie de intentos de relocalizarse en el sur, espacio privado. En ello no lograron su objetivo de manera permanente, y solo entre 1989 y el 2000 logró Susana permanecer en un área cercana al curso de agua, denominada "Corral Grande", teniendo luego que trasladarse nuevamente, más allá del límite de la propiedad privatizada con fines forestales -a la zona conocida como "Bardas Blancas". De forma que, como se puede observar en la figura 5, las desterritorializaciones atravesadas hasta el año 2000 implicaron una movilidad espacial en sentido norte, a pesar de las tentativas de retornar al valle.

\footnotetext{
${ }^{58}$ Los fundadores de la comunidad escaparon en contexto de una disputa territorial en 1919. Mabel Campo, logko (cabeza de comunidad) de Campo Maripe. Entrevista, Lof Campo Maripe, Neuquén, diciembre de 2019.

59 Mabel Campo. Testimonio en la audiencia del 16 de abril de 2019. Causa No 31.024, "Campo, Albino y otros s/ usurpación (art.181)". Registro audiovisual de la autora. Solo constarán los datos personales de los imputados en la causa y de personas públicas. Los demás testigos serán referenciados con un número acorde a la utilización de los testimonios en este escrito.

${ }^{60}$ Hecho que la comunidad endilga a los privados, que niegan su participación en el evento. Testigo 1. Testimonio en la audiencia del 13 de abril de 2019. Causa No 31.024, "Campo, Albino y otros s/ usurpación (art.181)". Registro audiovisual de la autora.
} 


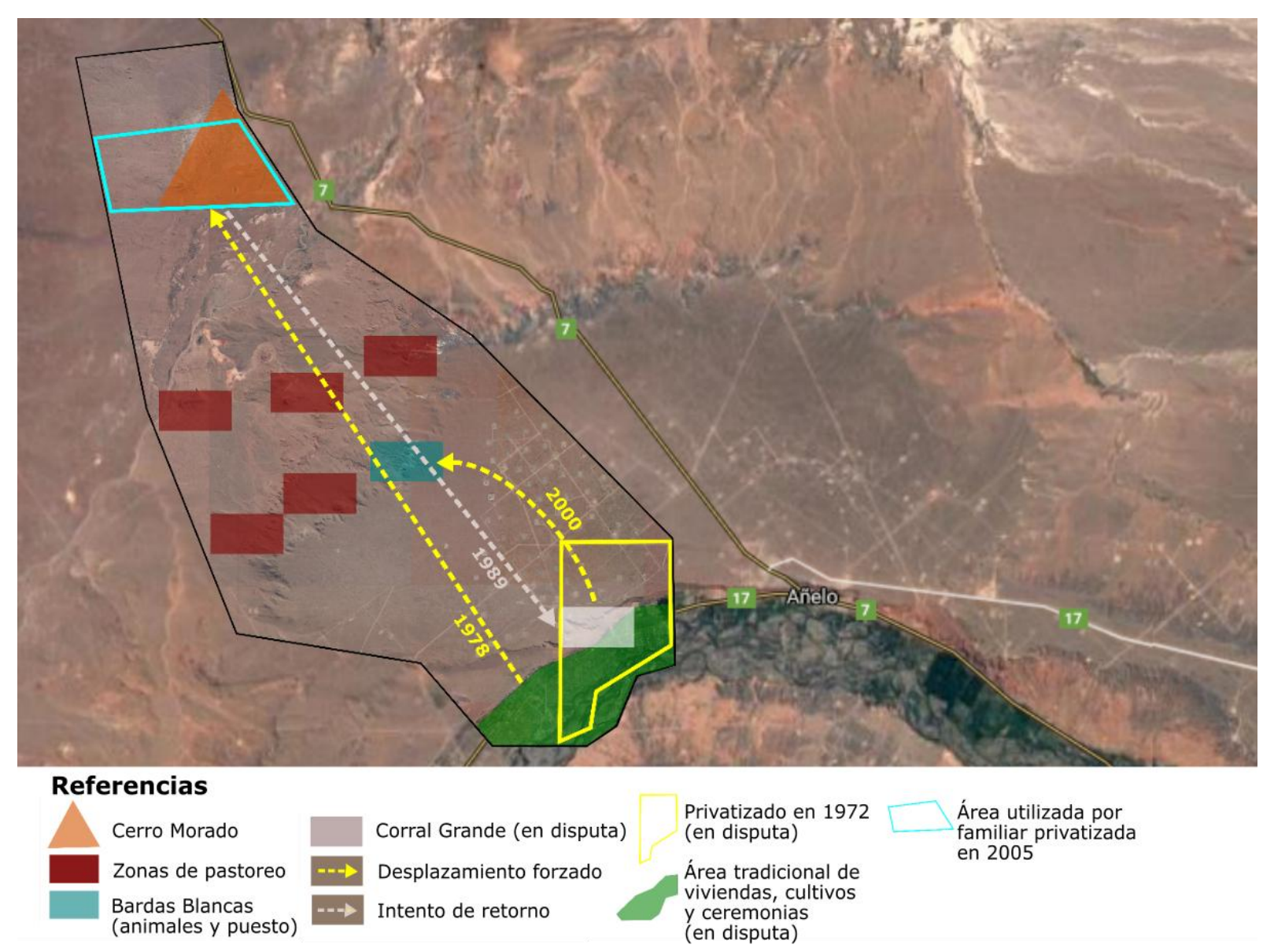

Fig. 5: Desterritorialización en sentido norte (1978-2000). Fuente: Elaboración propia ${ }^{61}$.

Para el cambio de siglo, aunque una parte de la familia aún persistía marginalmente en el territorio tradicional, los Campo Maripe se hallaban en dispersión debido a la desterritorialización. En el 2005 una parcela al norte, en la meseta, fue privatizada en favor de un familiar llegado a la zona en 1984 y que posteriormente no formó parte de la recomposición como comunidad, con lo cual se dio una importante pérdida de espacios que ya anunciaba la tendencia de la segunda desterritorialización (esta área se encuentra señalada en la figura 5). La imposibilidad, para los mapuce, de acceder a la propiedad de las superficies habitadas y la preferencia a nivel de las políticas provinciales por la ley № 263 para gestionar el reclamo de tierras suscitó entonces la aparición de una categoría más de agente en búsqueda de territorializarse: el indígena que decidió no formar parte del armado comunitario sino acceder a partir de la mencionada normativa a la propiedad privada individual. Esto da cuenta de las múltiples trayectorias identitarias y posibilidades de enraizamiento en el territorio ${ }^{62}$. La privatización del 2005 abrió el nuevo siglo como un momento en el que el panorama territorial iba a aumentar su complejidad.

\footnotetext{
${ }^{61}$ En base a trabajo de campo y VILLARREAL, Jorgelina y HUENCHO, Luisa. Informe... Op. cit.

62 BRIONES, Claudia. Caminos de enraizamiento en la mapu: procesos de formación de comunidad en la Norpatagonia argentina. En: BRIONES, Claudia y RAMOS, Ana (comps.). Parentesco y política. Topologías indígenas en la Patagonia. Viedma: Universidad Nacional de Río Negro, 2016, pp. 53-69.
} 
Con el inicio del avance hidrocarburífero al norte del río Neuquén, desde el 2011, se volvieron aún más rigurosas las condiciones para sostener la presencia en el territorio, puesto que las características de esta actividad se encontraron en plena contradicción con las de la ganadería extensiva, por la contaminación generada, así como por la presencia de las excavaciones mismas que ocupaban espacios de pastoreo en la meseta. A diferencia de la etapa previa de desterritorialización, en el nuevo siglo el contexto se había modificado, y había crecido en la provincia el nivel de organización indígena, a partir del organismo supracomunitario, la Confederación Mapuce de Neuquén, que había atravesado un proceso de consolidación de un proyecto nacional basado en la relación entre identidad, autonomía y territorio ${ }^{63}$.

Los miembros de la tercera generación -siete hermanos y sus familias- de Campo Maripe empezaron a organizarse nuevamente en el territorio, para lo cual tuvieron el acompañamiento de la Confederación Mapuce de Neuquén. En el 2013 se iniciaron los trámites para la obtención de la personería jurídica, que sin embargo sería denegada en ese momento. El Estado provincial intervino con la intención de garantizar el desarrollo hidrocarburífero, negando el derecho de la comunidad a habitar la meseta. A diferencia de la desterritorialización anterior a causa de la cual la comunidad se desestructuró, se abrió entonces un conflicto más intenso en cuyo contexto se consolidó la organización y en el cual se intentó una nueva desterritorialización, esta vez en sentido sur.

Sostenemos que el conflicto desatado a partir del 2011 con la comunidad mapuce, a diferencia del que sucedió en los setenta, involucró activamente al Estado neuquino, que intervino en todo momento con la finalidad de garantizar el desarrollo hidrocarburífero. El gobierno de Jorge Sapag no reconoció a Campo Maripe como comunidad mapuce, es decir, no inscribió su personería jurídica, hasta el 2014, tras la firma de un Acuerdo de Paz Social. Esto se produjo solo luego de que la organización decidiera ocupar una torre petrolera por varias jornadas, y como parte del pacto se realizó un relevamiento territorial que reunió información sobre la presencia histórica en la meseta. Sin embargo, esto no significó legitimar, desde el punto de vista estatal, la territorialidad indígena, con lo cual la disputa no cesaría.

Tras lo anterior el Ejecutivo otorgó una reserva de solo 63, 8 hectáreas en la margen norte del río Neuquén. Es decir, en esta nueva etapa, aquel espacio cercano al cuerpo de agua del cual habían sido expulsados en los setenta se presentaba como la opción de reasentamiento -en una superficie muy magra- frente a la necesidad de despejar el área mesetaria. Con esto se ponía de manifiesto un nuevo diseño del espacio, en el que los indígenas una vez más tendrían poco poder real de decisión, y una nueva desterritorialización con un sentido hacia el sur. En la figura 6 se observa la localización de la reserva, así como los espacios reclamados y los concedidos para la explotación hidrocarburífera.

\footnotetext{
${ }^{63}$ AGUIRRE, Sabrina. Procesos extractivos, territorio y autonomía indígena. El pueblo mapuche en Neuquén. Temas Sociológicos [en línea]. 2020, n. 27, pp. 449-487. [Consulta: 28-07-2021]. Disponible en $<$ http://ediciones.ucsh.cl/index.php/TSUCSH/article/view/2496/2130>.
} 


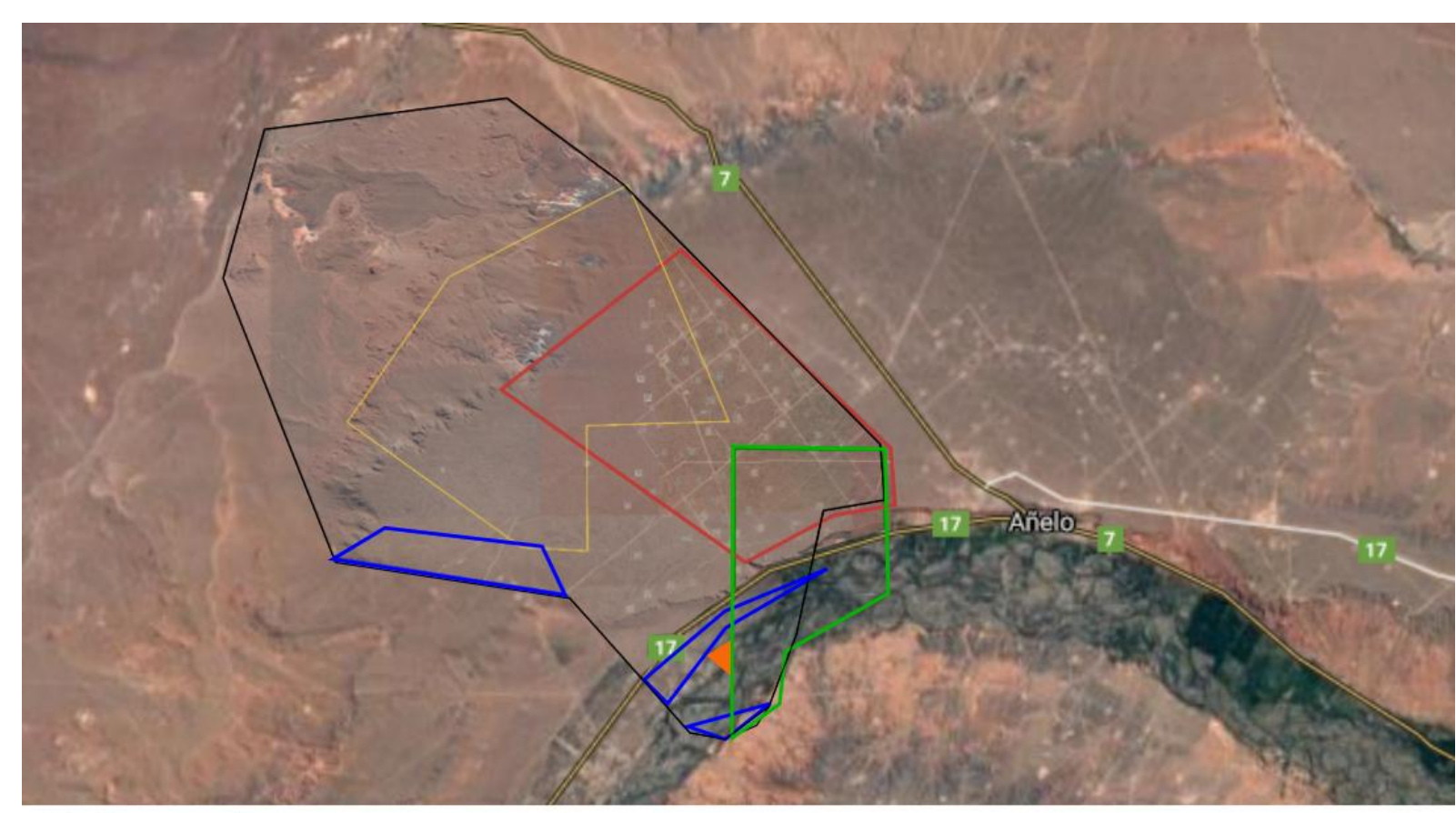

\section{Referencias}

Fig. 6: Nudo territorial en el siglo XXI. Fuente: Elaboración propia ${ }^{64}$.

A pesar de esta tendencia expulsora hacia el sur, la comunidad ya se encontraba reconstituida y articulada con la agrupación supracomunitaria, la Confederación Mapuce de Neuquén. Si los nudos territoriales implican el avance de una apropiación espacial sobre las formas de reproducción de diversos actores en un contexto de desigualdad de condiciones, en este caso la agudización de la disputa se debió al momento organizativo a nivel de pueblo indígena. A partir de los años noventa se había gestado un proyecto nacional mapuce, en el que la centralidad del territorio para reconstituir y reproducir la identidad implicaba la necesidad de una cierta autonomía en las decisiones territoriales, lo que alentó a los mapuce a persistir en sus reclamos ${ }^{65}$.

En el contexto de consolidación de este proyecto se reinició el armado comunitario de Campo Maripe, fuertemente acompañado por la organización supracomunitaria. Esto además pudo apoyarse sobre la legitimidad otorgada a los reclamos por las nuevas normativas en materia de derecho indígena vigentes a nivel internacional -con el Convenio 169 de la Organización Internacional del Trabajo- y nacional -con la Constitución Nacional reformada en $1994^{66}$. Todo ello configuró una

\footnotetext{
${ }^{64}$ En base a VILLARREAL, Jorgelina y HUENCHO, Luisa. Informe... Op. cit.

65 Confederación Mapuce de Neuquén. Propuestas para un kvme felen mapuce. Neuquén: Confederación Mapuce de Neuquén, 2010.

${ }^{66}$ Este conjunto de normativas consolidó un mejor estatus legal para los pueblos indígenas dentro de un paradigma general orientado a la aplicación de derechos específicos en función de la histórica subalternización de estos pueblos, que vino a reemplazar el anterior punto de vista anclado en la existencia de aquellos como minorías a integrar. Para mayor información se puede consultar GOMIZ,
} 
nueva posibilidad de resistir a la desterritorialización que implicaba el nuevo diseño del espacio por parte del Estado.

Al avance inconsulto sobre la meseta, Campo Maripe respondió con una reapropiación territorial, en un ejercicio directo de los derechos sobre el suelo, prescindiendo de la autorización estatal. Esta acción, aunque por fuera de la ley predilecta para gestionar los conflictos -la de tierras fiscales- logró instaurar un modo de proceder en el territorio por el cual diversos actores debieron reconocer en la práctica la existencia de la comunidad. Este contra-diseño del espacio supuso que algunas empresas de hidrocarburos entablaran una relación directa con la comunidad en diferentes momentos, basada en un diálogo con las autoridades de Campo Maripe en el caso de necesitar atravesar el territorio mapuce. Así lo aseveró el exlogko (ex cabeza de comunidad) Albino Campo en un juicio penal del año 2019 en el que seis integrantes fueron imputados.

\begin{abstract}
"Si nosotros nos ponemos a charlar con una empresa, tenemos buenas relaciones. Con Pluspetrol, para que sepa el señor abogado, muy buenas relaciones porque Pluspetrol fue una de las empresas que se acercó a tierras [Dirección Provincial de Tierras] a pedir el relevamiento ese [Informe del Relevamiento realizado en el marco del Acuerdo de Paz Social del 2014]. Se acercó a hablar con nosotros y cómo iba a trabajar... Nos informó, nos tiene informados, están trabajando con personal de medio ambiente"67.
\end{abstract}

Otras empresas, por el contrario, actuaron frente a la presencia indígena buscando utilizar las fuerzas de seguridad para garantizar sus actividades, como lo hizo YPF en 2017, cuando logró que Gendarmería Nacional ingresara al territorio ${ }^{68}$. Esto significa que la disputa territorial con las compañías no respondió siempre a las mismas pautas, aunque es necesario resaltar que la mencionada YPF es la mayor operaria de la zona. El proceder de Gendarmería en aquella ocasión, que ingresó durante dos días al espacio comunitario e impidió la movilidad de quienes se encontraban en él para permitir las actividades de $\mathrm{YPF}^{69}$, también contrastó con el tono predominante de las relaciones con las fuerzas de seguridad locales.

Los testimonios de oficiales de policía relataron eventos en los cuales los agentes acudían a la zona en conflicto para notificar a los mapuce acerca de los procesos judiciales en marcha. El marco del respeto mutuo, la ausencia de violencia durante los intercambios, el no ingreso al territorio para realizar las notificaciones y la identificación de las autoridades indígenas como las personas a las cuales dirigirse permiten señalar una aceptación en la práctica de la existencia de la comunidad. Los

\footnotetext{
Micaela y SALGADO, Juan Manuel. Convenio 169 de la OIT sobre Pueblos Indígenas: su aplicación en el derecho interno argentino. Neuquén: Observatorio de Derechos Humanos de Pueblos Indígenas, 2010. 408 p.

${ }^{67}$ Albino Campo. Testimonio en la audiencia del 16 de abril de 2019. Causa No 31.024, "Campo, Albino y otros s/ usurpación (art.181)". Registro audiovisual de la autora.

${ }^{68}$ Cámara Federal de Apelaciones de General Roca. Sentencia en "Comunidad Lof Campo Maripe (Loma de Campana) s/Habeas Corpus". 26 de septiembre de 2018. Expediente No FGR 11180/2017.

69 Ibídem. El procedimiento judicial posterior, a raíz de la presentación de un recurso de habeas corpus por parte de la comunidad, reveló que el ingreso de Gendarmería había sido ordenado vía telefónica por el entonces jefe de gabinete de la Ministra Nacional de Seguridad, Patricia Bullrich, quien formaba parte del gobierno de Mauricio Macri (2015-2019).
} 
oficiales de policía sostuvieron discursos que denotaban un reconocimiento de los procesos de autoidentificación:

"[Fiscal:] - ¿Cómo estaban vestidas estas personas?

[Testigo:] - Como se identifican, como mapuces.

[Fiscal:] - ¿Tenían algún elemento? ¿Portaban algún elemento?

[Testigo:] - Pancartas

[Fiscal:] - ¿Pancartas de qué?

[Testigo:] - De identificación que son la comunidad"70.

Es decir, el nudo territorial también implicó en este caso un solapamiento de institucionalidades, al ser reconocida en los hechos la institucionalidad indígena por algunos sujetos que actúan en el territorio con el fin de facilitar sus propios quehaceres. Esta actitud, sin embargo, fue contraria a la encarnada por el Estado provincial. En un primer momento, cuando en el año 2013 Campo Maripe solicitó la inscripción en el registro provincial de comunidades, la Dirección Provincial de Personas Jurídicas denegó el pedido sobre la base de que:

"El relato de los presentantes respecto a su reseña histórica se erige superfluo, endeble en sustento y no se acredita en este sentido el reconocimiento que refiere la ley, ya que dicha decisión no se dirige a un grupo de familias que se reagrupan en comunidades para acogerse a los beneficios acordados por ella, sino que, en otros términos, el reconocimiento en el contexto histórico se refiere a pueblos originarios preexistentes, con identidad propia, étnica..."71.

Es decir, la postura asumida por esta agencia estatal fue la de una inexistencia de una comunidad y de una identidad, para sostener que los Campo Maripe eran una familia que se agrupaba para acogerse a los beneficios de una ley. En la práctica esto supone una negación del principio de definición de una comunidad en base al criterio de la autoidentificación y coloca al Estado provincial en el rol de detector de rasgos objetivos de identidad étnica.

La versión oficial de Neuquén frente al caso de Campo Maripe ha sido que no hay una comunidad preexistente, que "no hay derechos ancestrales, sino un señor que vino de Chile [y] pidió un pastoreo en el año 40"72, en palabras del exgobernador Jorge Sapag. A pesar de ello, tras el mencionado evento de la toma de una torre petrolera en 2014, el gobierno, como ya se señalara, firmó con Campo Maripe un Acuerdo de Paz Social que establecía la no obturación de las actividades hidrocarburíferas a cambio del otorgamiento de la personería jurídica y de la realización de un relevamiento territorial que produjera un informe histórico y antropológico de la presencia indígena en la zona. Este documento fue elaborado en el 2015, aunque, tras el anuncio de sus resultados, la provincia lo desconoció y por el contrario se basó en uno propio, que no ha tomado estado público. A partir de esto, se denegó todo tipo de derecho territorial sobre la meseta, permitiendo así que

\footnotetext{
70 Testigo 2. Testimonio en la audiencia del 15 de abril de 2019. Causa № 31.024, "Campo, Albino y otros s/ usurpación (art.181)". Registro audiovisual de la autora.

71 Testigo 3. Testimonio en la audiencia del 16 de abril de 2019. Causa No 31.024, "Campo, Albino y otros s/ usurpación (art.181)". Registro audiovisual de la autora.

72 Observatorio cuestiona al gobernador. Río Negro [en línea]. 08-08-2015. [Consulta: 05-05-2021]. Disponible en <https://www.rionegro.com.ar/observatorio-cuestiona-al-gobernador-MBRN 7882352/>.
} 
Añelo continuara siendo un tenso nudo de territorialidades.

\section{Conclusiones}

La creación de un nudo territorial en Añelo respondió al progresivo solapamiento de múltiples sujetos en búsqueda de territorializarse. La marginalidad de este espacio a lo largo de casi todo el siglo XX significó que actores descapitalizados, como los Campo Maripe, se asentaran allí para llevar adelante actividades ganaderas extensivas sobre todo de caprino. Una primera etapa de diseño del espacio buscó generar grandes y medianas propiedades para radicar habitantes, empresas agrícolas para exportación de frutas y compañías forestales. Esto implicó la extensión de obras de riego, la privatización de algunas superficies a lo largo del valle del río Neuquén y la puesta en producción de campos que empezaron a avanzar sobre los espacios previamente habitados por los indígenas.

Aunque la actividad hidrocarburífera -radicada hasta el nuevo siglo sobre todo el sur del río Neuquén- no supuso en aquel momento una contradicción con el uso del espacio de los Campo Maripe, la territorialización de los agentes vinculados a los planes de desarrollo agrícola y forestal implicó un solapamiento de territorialidades que llevó al desmembramiento de la comunidad. Estos mapuce existían en ese entonces de forma aislada respecto de las otras comunidades presentes en la zona, lo que suponemos un factor clave para explicar la no organización colectiva de un reclamo. Por el contrario, las posibilidades de persistir en el territorio se redujeron a la permanencia individual y sujeta a sucesivas desterritorializaciones.

Cuando el espacio se volvió foco de una nueva territorialidad, la vinculada a los procesos de extracción de hidrocarburos por métodos no convencionales, ya habían sucedido dos vuelcos en las políticas del Estado neuquino. Se había definido el perfil hidrocarburífero, por un lado, y por el otro, se había virado desde el otorgamiento de reservas indígenas a la preferencia por una titularización individual sin implicancias étnicas a partir de la ley de tierras fiscales. Además, había tenido lugar un cambio con grandes implicancias en la zona, relativo a la elevación del nivel organizativo interno mapuce. La consolidación de un proyecto nacional autónomo que sustentó los procesos de reconstitución comunitaria como el de Campo Maripe supuso la creación de un reclamo colectivo en clave étnica que previamente no había sido viable.

Las territorialidades solapadas se articularon de formas complejas: a la oposición de los mapuce se superpuso la aceptación de otros actores que lograron transformar sus actividades, especialmente a partir del cobro de cánones como superficiarios. Al mismo tiempo, la decisión de no legitimar la existencia comunitaria y de preferir el reconocimiento de derechos sobre la tierra a individuos a partir de la ley № 263 supuso la emergencia de otro tipo de actor: el indígena que realizara una apropiación a título personal y por fuera del armado colectivo. La complejidad del solapamiento de territorialidades también se manifestó dentro del grupo de empresas hidrocarburíferas, ya que algunas optaron por reconocer en la práctica la institucionalidad indígena para facilitar las labores en el campo, mientras otras recurrieron al uso de la fuerza pública para ello. 
Es necesario resaltar que, en cuanto a la actitud estatal hacia la comunidad estudiada, la negación ha sido siempre la tónica dominante, no así la respectiva a otros actores en el territorio. Esto implica la posibilidad de analizar el rol del Estado provincial en la desestructuración de la comunidad analizada -dada desde la década de 1970 hasta la de 2010. El caso de Campo Maripe, al estar plenamente atravesado tanto por las consecuencias de la violencia estatal del siglo XIX como por las políticas provinciales más recientes, invita a asumir la posibilidad de estudiar la desterritorialización indígena como constitutiva de la provincia, en tanto posibilitó la consolidación del Estado neuquino en lo relativo a la apropiación de los espacios para explotarlos económicamente.

\section{Bibliografía y fuentes}

AGN-AI, Fondo Ministerio del Interior, Expedientes Generales, Caja 109, Expediente № 117117, COPADE, Informe sobre el proyecto de colonización de Guañacos.

AGUIRRE, Sabrina. Procesos extractivos, territorio y autonomía indígena. El pueblo mapuche en Neuquén. Temas Sociológicos [en línea]. 2020, n. 27, pp. 449-487. [Consulta: 28-07-2021]. Disponible en <http://ediciones.ucsh.cl/index.php/TSUCSH/article/view/2496/2130>.

ARIAS BUCCIARELLI, Mario. Identidades en disputa. Las regiones del Comahue y los poderes provinciales. Cuadernos del Sur [en línea]. 2007, n.35/36, pp. 1-17. [Consulta: 28-07-2021]. Disponible en < http://bibliotecadigital.uns.edu.ar/pdf/csh/n35-36/n35-36a06.pdf>.

BALAZOTE, Alejandro y RADOVICH, Juan Carlos. Proyecto Mega: disputa territorial y reconocimiento étnico de los mapuche de Kaxipayiñ. Relaciones de la Sociedad Argentina de Antropología. 2001, n. 26, pp. 110-117.

BANDIERI, Susana. Condicionantes históricos del asentamiento humano después de la ocupación militar del espacio. En: BANDIERI, Susana; FAVARO, Orietta y MORINELLI, Marta (comps.). Historia de Neuquén. Buenos Aires: Plus Ultra, 1993, pp. 109-146.

BILDER, Ernesto y GIULIANI, Adriana. La Economía Política de la Provincia de Neuquén (1983-2008). En: XII Jornadas Interescuelas de Departamentos de Historia. San Carlos de Bariloche: Universidad Nacional del Comahue, 2009.

BLANCO, Graciela. El petróleo en Neuquén: 100 años de historia (1918-2018). Neuquén: Provincia de Neuquén, 2018. 244 p.

BONILLA, Omar [et al.]. Nudos territoriales críticos en Ecuador: dinámicas, cambios y límites en la reconfiguración territorial del Estado. GeoGraphos [en línea]. 2016, vol. 7, n. 84, pp. 66-103. [Consulta: 04-05-2021]. Disponible en $<$ https://rua.ua.es/dspace/bitstream/10045/53465/1/Omar Bonilla.pdf>.

BORG RASMUSSEN, Mattias y LUND, Christian. Reconfiguring frontier spaces: the territorialization of resource control. World Development. 2018, n. 101, pp. 388- 
399.

BRIONES, Claudia. Caminos de enraizamiento en la mapu: procesos de formación de comunidad en la Norpatagonia argentina. En: BRIONES, Claudia y RAMOS, Ana (comps.). Parentesco y política. Topologías indígenas en la Patagonia. Viedma: Universidad Nacional de Río Negro, 2016, pp. 53-69.

CABRAL MARQUES, Daniel. Una relectura histórica de los impactos socioterritoriales de las megainversiones promovidas en el marco de la Patagonia Austral Argentino-Chilena: ¿Distintas formas de desarrollo inducido o meras estrategias de espacialización desregulada de vectores de expansión capitalista? Perfiles Económicos [en línea]. 2016, n. 1, pp. 119-145. [Consulta: 28-07-2021]. Disponible $<$ https://revistas.uv.cl/index.php/Perfiles/article/view/609>.

Cámara Federal de Apelaciones de General Roca. Sentencia en "Comunidad Lof Campo Maripe (Loma de Campana) s/Habeas Corpus". 26 de septiembre de 2018. Expediente № FGR 11180/2017.

CDCT. Registro № 2620-222. Consejo de Planificación y Acción para el Desarrollo (en adelante COPADE). Cursos de acción a corto plazo. Tomo III. 1977, p. 5.

CDCT. Registro № 3331-318. Provincia del Neuquén. Plan de desarrollo provincial. Anexo I: Bases para la formulación del Plan de Desarrollo Provincial. 1969.

CDCT. Registro № 4445-473. COPADE. Neuquén. Estrategia para el desarrollo. 1988.

CDCT. Registro № 5595-608. COPADE. Neuquén 2020: Crisis y oportunidad. 1997.

CDTC. Biblioteca General. Registro № 4438. COPADE. Síntesis Regional. Región Añelo Pehuenches. Documento de Trabajo № 4 del Proyecto "Instrumentación del sistema provincial de planificación del desarrollo". 2011.

Confederación Mapuce de Neuquén. Propuestas para un kvme felen mapuce. Neuquén: Confederación Mapuce de Neuquén, 2010.

Corte Suprema de Justicia de la Nación. Fallo en "Confederación Indígena del Neuquén c/ Provincia del Neuquén s/ acción de inconstitucionalidad". 10 de diciembre de 2013. Expediente № 615/02.

Cuatro generaciones en Añelo. Río Negro [en línea]. 20-10-2015. [Consulta: 05-052021]. Disponible en <https://www.rionegro.com.ar/cuatro-generaciones-enanelo-FCRN 7970606/>.

DALMAUX, Ana María y MICHAU, Analía. Proceso de ocupación del Valle de Añelo [tesis de licenciatura]. Neuquén: Universidad Nacional del Comahue, 1989. 79 p.

DELRIO, Walter [et al.]. En el país de nomeacuerdo. Archivos y memorias del 
genocidio del Estado argentino sobre los pueblos originarios, 1870-1950. Viedma: Universidad Nacional de Río Negro, 2018. 325 p.

DI RISIO, Diego [et al.]. (comps.). Zonas de sacrificio. Impactos de la industria hidrocarburífera en Salta y Norpatagonia. Buenos Aires: América Libre, 2012. $248 p$.

DÍAZ, María Noemí. Evaluación de componentes regionales por microregión y selección de una muestra. Neuquén: COPADE, 1997. 96 p.

Dirección Nacional de Información Energética. Mapa "Vaca Muerta” [en línea]. 2019. [Consulta: 05-05-2021]. Disponible en $<$ http://www.energia.gob.ar/contenidos/archivos/Reorganizacion/mesa vaca mu erta/mapa vm/VACA\%20MUERTA v6 03-01-2019.pdf>.

FALASCHI, Carlos; SÁNCHEZ, Fernando y SZULC, Andrea. Políticas indigenistas en Neuquén: pasado y presente. En: BRIONES, Claudia (ed.). Cartografías Argentinas. Políticas indigenistas y formaciones provinciales de alteridad. Buenos Aires: Antropofagia, 2005, pp. 179-221.

FAVARO, Orietta (comp.). Sujetos sociales y políticas. Historia reciente de la Norpatagonia Argentina [en línea]. Buenos Aires: La Colmena, 2005. 223 p. [Consulta: 04-05-2021]. Disponible en $<$ http://biblioteca.clacso.edu.ar/Argentina/cehepycuncoma/20110414103131/favaro.pdf >.

FAVARO, Orietta y ANGELINI, Cristina. La situación de las tierras fiscales en la provincia del Neuquén (1957-1977). En: BANDIERI, Susana; LOTITO, María Cristina y VARELA, Gladys (comps.). Neuquén: un siglo de historia. Neuquén: Universidad Nacional del Comahue; Cooperativa de Agua Luz y Fuerza, 1983, pp. 159-165.

FAVARO, Orietta. Estado, política y petróleo. La historia política neuquina y el rol del petróleo en el modelo de provincia, 1958-1990 [tesis doctoral]. La Plata: Universidad Nacional de La Plata, 2001. [Consulta: 05-05-2021]. Disponible en $<$ http://www.memoria.fahce.unlp.edu.ar/library?a=d\&c=tesis\&d=Jte131>.

GOMIZ, Micaela. La propiedad comunitaria indígena en la provincia de Neuquén. En: III Congreso Nacional de Derecho Agrario Provincial. Neuquén, 2015.

GOMIZ, Micaela y SALGADO, Juan Manuel. Convenio 169 de la OIT sobre Pueblos Indígenas: su aplicación en el derecho interno argentino. Neuquén: Observatorio de Derechos Humanos de Pueblos Indígenas, 2010. 408 p.

HAESBAERT, Rogerio. Del mito de la desterritorialización a la multiterritorialidad. Cultura y representaciones sociales [en línea]. 2013, vol. 8, n. 15, pp. 9-42. [Consulta: 04-05-2021]. Disponible en $<$ http://www.scielo.org.mx/pdf/crs/v8n15/v8n15a1.pdf>. 
HAESBAERT, Rogerio. El mito de la desterritorialización. Del "fin de los territorios" a la multiterritorialidad. México: Siglo XXI, 2011. 328 p.

KUGLER, Norberto. Programa de diversificación productiva y modernización del Estado de la Provincia del Neuquén. Neuquén: Ministerio Nacional de Economía y Obras y Servicios Públicos, 1998. 90 p.

Las polémicas renegociaciones de concesiones petroleras de Sapag. Noticias [en línea]. 16-02-2018. [Consulta: 05-05-2021]. Disponible en $<$ https://noticias.perfil.com/noticias/general/2018-02-16-las-polemicas-

renegociaciones-de-concesiones-petroleras-de-sapag.phtml>.

LEFEBVRE, Henri. La producción del espacio. Papers: revista de sociología. 1974, n. 3, pp. 219-229.

LENTON, Diana. Política indigenista argentina: una construcción inconclusa. Anuário antropológico [en línea]. 2010, v. 35, n. 1, pp. 57-97. [Consulta: 04-05-2021]. Disponible en <https://journals.openedition.org/aa/781>.

MARAGGI, Inés. Conflictos territoriales y resistencia mapuche en Loma La Lata y Loma Campana, Neuquén, Argentina. Boletín Geográfico [en línea]. 2020, vol. 42, n. 1, pp. 35-55. [Consulta: 04-05-2021]. Disponible en $<$ http://revele.uncoma.edu.ar/htdoc/revele/index.php/geografia/article/view/2701/ $\underline{59490}>$.

Mendoza Gobierno. 1947 - Cuarto censo General de la Nación. Tomo II [en línea]. [Consulta: 05-05-2021]. Disponible en $<$ http://www.deie.mendoza.gov.ar/\#!/censos-productivos/1947-cuarto-censogeneral-de-la-nacion-42>.

MOTTURA, David. En Vaca Muerta están 7 de 10 pozos petroleros más productivos. Más energía [en línea]. 07-02-2020. [Consulta: 05-05-2021] Disponible en $<$ https://mase.Imneuquen.com/vaca-muerta/en-estan-7-cada-10-pozospetroleros-mas-productivos-n682830>.

PAPAZIAN, Alexis. Pliegues genocidas en Estados nacientes: el genocidio armenio en Turquía y el genocidio indígena en Argentina. Revista de Estudios sobre Genocidio [en línea]. 2018, n. 13, pp. 11-25. [Consulta: 04-05-2021]. Disponible en <http://revistas.untref.edu.ar/index.php/reg/article/view/255 $>$.

PÉREZ ROIG, Diego. La expansión de la frontera hidrocarburífera en Neuquén durante los 2000. Un análisis de sus causas y consecuencias. En: IV Jornadas de Becarios y Tesistas. Buenos Aires: Universidad de Quilmes, 2014.

PERREN, Joaquín. "Erase una vez en la Patagonia". Luces y sombras de la economía neuquina (1958-1991). Observatorio de la Economía de la Patagonia [en línea]. 2007. [Consulta: 04-05-2021]. Disponible en $<$ https://www.eumed.net/oe-pat/>. 
PERREN, Joaquín. "Una transición demográfica en el fin del mundo". La población de la provincia de Neuquén (Patagonia, Argentina) durante el siglo XX tardío. Scripta Nova [en línea]. 2009, vol. 13. [Consulta: 28-07-2021]. Disponible en $<$ http://www.ub.edu/geocrit/sn/sn-282.htm>.

RADOVICH, Juan Carlos. Fractura hidráulica y conflicto territorial en la comunidad mapuche Campo Maripe, Neuquén, Argentina. Revista GeoPantanal [en línea]. 2017, vol. 12, n. 22, pp. 89-104. [Consulta: 04-05-2021]. Disponible en $<$ https://periodicos.ufms.br/index.php/revgeo/article/view/3806 >.

RAFART, Gabriel. Las "partes" del Movimiento Popular Neuquino. Un ensayo de interpretación de sus tiempos partidarios. Revista de la Facultad de Derecho y Ciencias Sociales [en línea]. 2009, n. 15, pp. 93-113. [Consulta: 05-05-2021]. Disponible $<$ https://fadeweb.uncoma.edu.ar/extension/publifadecs/revista/revista15/05Gabri elRafart.pdf $>$.

Observatorio cuestiona al gobernador. Río Negro [en línea]. 08-08-2015. [Consulta: 05-05-2021]. Disponible en <https://www.rionegro.com.ar/observatorio-cuestionaal-gobernador-MBRN 7882352/>.

RODRÍGUEZ, Edgardo. Análisis socioeconómico, aspectos culturales y tipología de las comunidades aborígenes del Neuquén. Neuquén: Consejo Federal de Inversiones, 1978. $153 \mathrm{p}$.

TRPIN, Verónica y RODRÍGUEZ, Daniela. Transformaciones territoriales y desigualdades en el norte de la Patagonia: extractivismo y conflictos en áreas agrarias y turísticas. Albuquerque: revista de historia [en línea]. 2018, vol. 10, n. 20, pp. 50-66. [Consulta: 05-05-2021]. Disponible en $<$ https://ri.conicet.gov.ar/handle/11336/89750>.

VALVERDE, Sebastián. La historia de las organizaciones etnopolíticas del pueblo mapuche. Revista de Historia [en línea]. 2005, n. 10, pp. 167-177. [Consulta: 0505-2021]. Disponible en $<$ http://revele.uncoma.edu.ar/htdoc/revele/index.php/historia/article/view/223>.

VILLARREAL, Jorgelina y HUENCHO, Luisa. Informe Histórico-antropológico. Relevamiento territorial Lof Campo Maripe. Pueblo Mapuce. Neuquén: Provincia de Neuquén. 247 p. 